\title{
¿El ocaso de Ia Doctrina Monroe? Colombia y Brasil, entre el norte de siempre y un sur renovado*
}

\section{The decline of the Monroe Doctrine? Colombia and Brazil, between a traditional north and a renewed south}

\author{
Ricardo Betancourt Vélez ${ }^{* *}$
}

Recibido: 12/02/2014

Aprobado: 26/03/2014

Disponible en línea: 01/07/2014

\section{Resumen:}

En los siglos XIX y XX, Estados Unidos definió a Latinoamérica como su 'patio trasero' a partir de la formulación de la Doctrina Monroe. Sin embargo, las transformaciones globales y regionales que se vienen desarrollando en el siglo XXI han debilitado dicha doctrina y han posibilitado la aparición de una nueva concepción de espacio, llamado Suramérica, como una interesante alternativa. En este artículo se analiza el papel de Brasil como potencia regional que lidera la construcción de este nuevo espacio. Asimismo analiza el papel de Colombia, tradicional aliado de Estados Unidos, ante la aparición del liderazgo brasileño.

\begin{abstract}
:
Since the formulation of the Monroe Doctrine, United States defined Latin America as his 'backyard' in the XIX ${ }^{\text {th }}$ and XX ${ }^{\text {th }}$ centuries. However, the global and regional transformations in the $\mathrm{XXI}^{\text {st }}$ century have weakened the Doctrine, and promoted a new idea of the space, named South America. This paper analyzes the role of Brazil as a regional power, which leads the creation of this new space. Furthermore, it analyzes the role of Colombia, a United States traditional ally, facing the Brazilian leadership.
\end{abstract}

doi:10.11144/Javeriana.PAPO19-2.odmc

\footnotetext{
* Este artículo presenta los resultados más relevantes de la investigación realizada para la elaboración del trabajo de grado para optar por el título de Magíster en Relaciones Internacionales de la Pontificia Universidad Javeriana. Por tal motivo, presenta varios de sus apartados.

** Politólogo de la Universidad Nacional de Colombia y Magíster en Relaciones Internacionales de la Pontificia Universidad Javeriana. Profesor de la Pontificia Universidad Javeriana y de la Universidad Militar Nueva Granada. Miembro de los grupos de investigación GRIALI y PIREO en dichas universidades. Correo electrónico: rbetancourt@javeriana.edu.co
} 


\section{Palabras clave:}

Doctrina Monroe; latinoamericanísmo; suramericanísmo; Brasil; Colombia

\section{Cómo citar este artículo:}

Currea-Lugo, V. (2014). ¿El ocaso de la Doctrina Monroe? Colombia y Brasil, entre el norte de siempre y un sur renovado. Papel Político, 19(2), 691-719. http://dx.doi.org/10.11144/ Javeriana.PAPO19-2.odmc

\section{Keywords:}

Monroe Doctrine; latinamericanism; southamericanism; Brazil; Colombia 


\section{Introducción}

Este artículo toma como contexto el fin de la bipolaridad propia de la Guerra Fría y el surgimiento de la multipolaridad definida por la emergencia de algunas potencias en diferentes latitudes del mundo que se han apoyado en sus entornos regionales para proyectar su poder globalmente. En el caso del continente americano, el surgimiento de Brasil ha modificado las lógicas del poder regional, debilitando el tradicional monroísmo estadounidense y planteando nuevos contenidos al latinoamericanismo, convirtiéndolo en una interesante alternativa que está transformando las relaciones entre el norte y el sur del continente.

\section{Un continente, varias Américas}

América nunca ha sido un espacio monolítico. A la par del desarrollo de la vida republicana, han existido diferentes procesos de fragmentación y de particularización de zonas, lo que hace posible hablar de la existencia de varias Américas, cada una definitoria de la forma en que se relacionan los países del continente. Una de las primeras interpretaciones del espacio fue la de la Pan América, que data de la Conferencia Internacional Americana de 1889 (Ardao, 2006, p. 159), y que le daba forma a la doctrina que en 1823 formuló el presidente estadounidense James Monroe según la cual el continente debía escindirse de la influencia europea, romper el vínculo colonial y ser exclusivamente una "América para los americanos" (Boorstin, 1997, p. 211).

Como extensión de la Doctrina Monroe, la idea de la Pan América contenía la representación del continente como el escenario natural y exclusivo para el desenvolvimiento de los intereses económicos, políticos, y eventualmente territoriales de Estados Unidos, además de encarnar la presunción mesiánica de un 'destino manifiesto’ que dotaba a la naciente potencia de superioridad moral, que de forma natural la autorizaba a tomar decisiones sobre el continente. Era asimismo un llamado a las potencias europeas para que renunciaran a sus intereses en América, contemplando la amenaza de intervención estadounidense en caso de que la influencia europea a este lado del Atlántico pusiera en riesgo los intereses de aquel país (Ardao, 2006, p. 159). El panamericanismo le daba forma a la política externa estadounidense a partir de la creencia en un destino manifiesto y entre tanto, el continente americano se representaba como el espacio en el que esa creencia debía materializarse.

El concepto y las ideas del Panamericanismo se van ajustando a los nuevos tiempos y toman la forma del Interamericanismo, pero mantienen la misma esencia de asumir a América como un espacio de influencia exclusiva e imponderable de Estados Unidos. Por eso, el Sistema Interamericano, encabezado por la Organización de Estados Americanos (OEA), surge precisamente como parte del ajedrez geopolítico de la superpotencia en el contexto de la Guerra Fría. Terminada la confrontación bipolar, la idea de la Pan América tomó la forma de Las Américas, siendo esta la base para la formulación del ALCA. 
En contraposición a estas definiciones provenientes del norte del continente, en el sur del mismo aparece la idea de Latinoamérica, concebida entre 1836 y 1861 (Ardao, 2006, p. 160). Dicha idea es heredera del Bolivarismo que argumenta la existencia de un espacio propio y autónomo conformado por pueblos con historias coloniales similares, principalmente encabezadas por los imperios ibéricos y que excluye a la América anglo y francófona del norte (Estados Unidos y Canadá).

Así definida, Latinoamérica es una idea que se contrapone a la del Monroismo en tanto no se representa como el escenario de expansión del Destino Manifiesto. Incluso la idea de que existe una historia y un destino común, conlleva a una voluntad de autonomía por parte de una 'nación' latinoamericana, ideas estas que ya se empezaban a esbozar en la Carta de Jamaica escrita por Bolívar en 1815 (Liévano Aguirre, 1988, p. 32 y ss). En debate con la Pan América que define un espacio geográfico y una zona de influencia de ideas e intereses estadounidenses, América Latina o Latinoamérica contempla la idea de una nación diversa, autónoma, pluriétnica y multicultural que en 1891 José Martí llamaba Nuestra América.

A pesar de iniciativas de identidad latinoamericanista como la Asociación Latinoamericana de Libre Comercio (ALALC) y la Comunidad Andina, si las dos posiciones encontradas se pusieran en una balanza, la historia del siglo XX seguramente se vería inclinada hacia la orilla del Panamericanismo. Los proyectos latinoamericanistas o bien fracasaron, o apenas llegan a cumplir parcial y limitadamente con sus objetivos; mientras que América Latina sí logró ser funcionalizada por Estados Unidos en su estrategia de contención del comunismo en el contexto de la Guerra Fría, en el que como bien se esgrimía en la Doctrina Monroe, la influencia de potencias extra-continentales se mantuvo a raya, dejando de ser para el caso, los imperios de Europa occidental las amenazas a repeler y tomando este rol la Unión Soviética. Esto llevó a que casi todo el subcontinente fungiera como retaguardia estratégica de la potencia del norte. En este contexto, cualquier proyecto que rivalizara con la influencia hegemónica de Estados Unidos en el continente, era considerado como una afrenta al Destino Manifiesto y merecía la acción contundente por parte de la potencia del Norte. De este razonamiento se derivó, entre otras cosas, el periodo de las dictaduras en América Latina.

Tanto durante la bipolaridad como en la primera década tras el fin de la misma, los proyectos que podrían considerarse latinoamericanistas se encontraron con el obstáculo de resultar contradictores de un Panamericanismo que durante ese periodo, era parte fundamental de la seguridad de Estados Unidos y por lo tanto, se enfrentaban a la fuerza opositora de la superpotencia. La potencia del norte llegaba a considerarlos una amenaza en la medida en que clamaban por autonomía en un tiempo en el que la estructura de poder internacional no permitía la existencia de alternativas a la bipolaridad, con la relativa excepción de algunos fenómenos concretos como el 
surgimiento de los No Alineados, el embargo petrolero de los países de la OPEP o la Revolución Fundamentalista Islámica.

No se está afirmando que Estados Unidos haya sido el responsable del fracaso de estos proyectos -aunque influyó en que eso ocurriera-, pues los mismos de cualquier forma han sido bastante débiles. Lo que se afirma es que la estructura internacional de poder bipolar de la Guerra Fría y posteriormente la creencia en el 'fin de la historia' que llevó a la reforma de los Estados bajo el parámetro homogenizante del Consenso de Washington, no permitieron que la idea del Latinoamericanísmo llegara a consolidarse como una institución con dinámicas propias y particularizantes que avanzaran en la construcción de una región.

\section{De Latinoamérica a Suramérica}

Si se rastrea la evolución de la idea de Latinoamericanísmo, se puede considerar a Suramérica como una de sus herederas. Si bien el tradicional Latinoamericanísmo sigue vivo, y aun cuando este nuevo espacio no abarca geográficamente el mismo territorio, contiene el mencionado acervo de ideas de un espacio autónomo -más no aislacionista-, conformado por países con historias y realidades similares, con un creciente nivel de interdependencia, que no incluye dentro de sus límites a la América anglosajona del norte, y que viene creando sus propias instituciones y organizaciones que definen la existencia de un adentro y un afuera. No se trata de un espacio consolidado y mucho menos libre de tensiones, y de hecho implica entrar en debate con la historia pues Colombia ha estado más cercana a la Pan América del ALCA y a la Interamerica de la OEA, mientras Brasil, al menos desde su proceso de democratización, le ha venido dando nuevo contenido a la Latinoamérica y más recientemente a la Suramérica (Betancourt, 2012b, p. 318).

Brasil llega a ser incluso protagonista de primer orden en la definición de Suramérica como una de las herederas del Latinoamericanísmo y a la vez, diferenciándose tanto en el espacio geográfico que ocupa como en el acervo de ideas que contiene. Tienen en común la voluntad de excluir a Estados Unidos y ganar autonomía frente a la superpotencia, pero en la versión brasileña, la relación con el país del norte no resulta conflictiva y de hecho llega a ser cooperativa en varios aspectos. Tradicionalmente, Brasil fue un país cercano a Estados Unidos que durante buena parte de su historia republicana, mantuvo una prudente y cordial relación con la superpotencia. Dicha relación se estrechó bastante en el periodo de la dictadura brasileña, pero a finales del siglo XX, con la transición a la democracia, se renovó el interés del gigante del sur en sus vecinos (Lafer, 2002, p. 72). Esto explica que sea en este periodo de tiempo que Spektor (2011, p. 161) ubique los primeros pasos hacia la suramericanización del Latinoamericanísmo en cabeza de Brasil.

El Plan Real para la estabilización macroeconómica de Brasil que tuvo lugar a mediados de la década de 1990 fue un elemento clave. Siendo esta una década caracterizada por la inestabilidad económica en el Cono Sur, Brasil, en aras de su propia estabilidad 
requería que el naciente proyecto del Mercosur desarrollara instituciones estables. Uno de los principales obstáculos para que esto ocurriera era que la tradicional rivalidad entre este país y Argentina, provocaba con frecuencia decisiones discordantes entre estas dos potencias del sur del continente, al punto de que Mercosur se convertía en espacio de impugnación permanente de Argentina al poder de Brasil.

La potencia regional llegó a la conclusión de que una forma apropiada de tratar este obstáculo era diluir el poder de Argentina en medio de la creación de un acuerdo regional amplio en el que participando más países, el peso relativo de Argentina se diluyera. La otra cara de esta estrategia, era que se debían estrechar los lazos entre Brasil y los demás países para que la influencia del gigante del sur sobre los mismos, llevara a la organización por un camino más conveniente para los intereses brasileños (Spektor, 2011, p. 163)

El éxito que tuvo la estabilización de la economía de Brasil en la década de 1990 propició que esta entrara en la senda del crecimiento, llegando a desarrollar un mercado interno importante y un sistema productivo de peso que produjo el estrechamiento de los vínculos comerciales entre este país y sus vecinos. Las crecientes relaciones comerciales expandieron los intereses económicos de Brasil hacia sus vecinos, por lo que las realidades internas de estos países se volvieron un motivo de preocupación para la potencia regional, lo que a su vez condujo a un incremento de los diálogos políticos intrarregionales.

El aumento de la interdependencia, así como la voluntad de la potencia regional de ganar preponderancia en la región y garantizar sus propios intereses (Hurrell, 2000) y la resistencia de las potencias secundarias a aceptar el seguimiento irrestricto a quien ejerce como poder regional, conlleva a que este último asuma el costo de proveer bienes colectivos que disminuyan la voluntad de sus contrapartes menos poderosas de avanzar estrategias de impugnación (Flemes, 2012, p. 33). Así, la creciente preocupación de Brasil por custodiar sus propios intereses en la región lo llevó a desempeñar un papel más activo, asumiendo un rol de liderazgo y llegando a proveer bienes colectivos como lo es la defensa de la estabilidad regional y el desarrollo de infraestructura de interconexión. Este comportamiento además, se amparó en la construcción de organizaciones regionales y de instituciones que le permitieran tener una injerencia mayor en la toma de decisiones al interior del mencionado espacio.

Un componente clave en el proceso de delimitación fue que la misma inestabilidad y las problemáticas internas de varios de los países en los cuales Brasil tenía intereses, eran motivo de preocupación para Estados Unidos y en consecuencia, se volvían receptores del accionar de la potencia del norte, lo que llegaba a rivalizar con los intereses brasileños. Así por ejemplo, la inestabilidad y problemáticas de Colombia en materia de seguridad y narcotráfico, enmarcadas en la tradicional cercanía entre dicho país y la superpotencia, convertía a este país en foco de interés de la misma, lo que desencadenaba acciones como la ejecución del Plan Colombia que llevaba la injerencia estadounidense hasta las propias 
fronteras de Brasil (Betancourt, 2012a, p. 664). Asimismo, el discurso crítico y confrontacional de Bolivia, Ecuador y Venezuela frente al tradicional hegemón, terminan convirtiéndose en prioridad y espacio de intervención norteamericana (Ramírez, 2011, p. 127).

También se puede considerar que un factor decisivo para delimitar a Suramérica como un nuevo espacio, fue la incomodidad por la presencia de México en Latinoamérica. Tras ser un líder natural en Latinoamérica, desde finales de la década de 1980 este país empezó a vivir un proceso de 'norteamericanización'. Mientras en una de sus caras mantenía la pretensión de jugar un rol preponderante en Latinoamérica y por lo tanto podía convertirse en fuente de impugnación frente al liderazgo de Brasil, en su otra cara se había convertido en un país norteamericano más, cercano a los intereses de Estados Unidos (Rocha y Morales, 2008). Estos dos motivos hacían de México un potencial contradictor de los intereses de Brasil y su presencia en el mismo espacio resultaba incomoda (Spektor, 2011, p. 163). Así, resultaba mucho más práctico y viable crear una nueva idea de espacio social, político y económico llamado Suramérica, que además de excluir a Estados Unidos y a Canadá, dejara a México en el 'afuera' (Lafer, 2002, p. 68).

El renovado interés de Brasil por construir organizaciones e instituciones regionales que le permitieran defender su posición frente a Estados Unidos, también encontró lugar en el Mercosur, en el que Cardoso pasó a defender la idea de que era necesario estrechar los vínculos y pasar de la simple zona de liberalización comercial, a la política comercial común y al arancel externo común, lo que ya empezaba a representar referentes de soberanía compartida (Amorim, 2009, p. 8). Paralelamente, Brasil estimuló el encuentro entre la Comunidad Andina de Naciones y el Mercosur, siendo esta otra muestra del tejido organizacional e institucional que se empezó a construir. Al respecto, el nuevo presidente de Brasil, Lula da Silva (citado en Arroyave, 2012, p. 254), mencionaba que: "nuestra prioridad en materia de integración es la América del Sur y estamos dispuestos a hacer lo que sea necesario para acelerar las negociaciones con la Comunidad Andina y sus miembros”. En suma, Brasil priorizó su política regional como estrategia para su interacción con el mundo y el encausamiento de su política hacia Suramérica, tuvo como protagonistas a Fernando Henrique Cardoso y a Lula da Silva (Arroyave, 2012, p. 253).

Pero probablemente el punto de quiebre que determinó el paso del Latinoamericanísmo al Suramericanísmo como alternativa al Monroísmo bajo el liderazgo de Brasil, fue la propuesta del gobierno estadounidense en el tiempo de Clinton de crear un área de libre comercio continental llamada ALCA (Área de Libre Comercio de Las Américas). La idea de establecer un área de libre comercio continental se convirtió en tema de discusión y debate. Mientras países como Venezuela y posteriormente, Bolivia y Ecuador asumieron una posición contraria y crítica respecto a esta propuesta, Colombia, México y Chile, tanto por su afinidad con el libre comercio como por su cercanía a Estados Unidos expresaban una voluntad favorable. Brasil por su parte, siendo gobernada en 
ese momento por Fernando Henrique Cardoso, tenía en cuenta la propuesta, pero la matizaba a consideración de que era viable siempre y cuando fuera el resultado de una negociación equilibrada entre el norte y el sur del continente. En este punto, la preocupación de Brasil no era en sí el desarrollo del libre comercio continental, lo cual de hecho apoyaba, sino que este esquema se adoptara bajo la batuta estadounidense y como resultado de una negociación asimétrica e incluso como una imposición.

Cardoso consideraba que era importante estudiar el asunto siempre y cuando fuera posible una negociación que volviera el acuerdo más equitativo y favorable para el sur de lo que se podía vislumbrar en caso de la imposición estadounidense. Brasil empezó a hacer llamados por la convergencia latinoamericana a favor de una posición conjunta que le permitiera al subcontinente asumir un rol negociador más fuerte. Sin embargo, de nuevo resultaba palpable la inconveniencia del concepto de Latinoamérica dado que la visión mexicana del subcontinente podría no distar mucho de la que proponía el ALCA, que se limitaba al libre comercio con beneficios asimétricos, pues como lo recuerda Huntington (2006), este país en las últimas décadas ha optado por ser norteamericano por encima de latinoamericano.

En consecuencia, se perfilaba en Brasil una intensión que tenía como horizonte a Suramérica y muestra de ello eran los discursos de Cardoso en los que con frecuencia expresaba que "Mercosur es un destino, ALCA una opción” (Roett, 2007, p. 56). Esto implicaba un cambio entre el seguidismo pro-estadounidense del gigante del sur en los albores del siglo XX y una nueva mirada con voluntad de autonomía y agencia de un proyecto propio ubicado en un espacio novedoso.

La estrategia de soft balancing brasileña consistió en estrechar los vínculos con varios países de Latinoamérica bajo la bandera de un propósito común frente a lo amenazante que podía resultar un área de libre comercio impuesta por Estados Unidos y aceptada sumisamente por el sur. La estrategia no consistía en entrar en confrontación con la superpotencia, sino simplemente en sumar poder en virtud de alianzas sur-sur que fortalecieran la posición de Brasil. El resultado fue que se llegó a conformar un bloque de países que encausaron su comportamiento hacia un objetivo común que era ofrecer resistencia conjunta y conseguir así una posición negociadora más favorable.

Sin embargo, Colombia no participó de esta alianza dado que no estaba dispuesta a contradecir a su tradicional aliado del norte y veía la iniciativa brasileña como un contrapeso ideológico del panamericanismo que había sido dominante de su política exterior (Pastrana, 2011a, p. 81). Hay que recordar al respecto que de cualquier forma Colombia no estaba en condiciones de alejarse de la superpotencia dado que en ese preciso momento negociaba los pormenores del que sería el Plan Colombia (Londoño, 2011, p. 245).

Si bien el proyecto del ALCA terminó por estancarse, la preocupación de Brasil no desapareció puesto que la estrategia norteamericana consistió entonces en concretar 
TLCs bilaterales. Asimismo, a pesar del aparente éxito de la alianza sur-sur que claramente excluía a Estados Unidos y que lo ponía como un 'afuera' contraparte de la negociación (Spektor, 2011, p. 161), la superpotencia no se quedaba con los brazos cruzados y aumentaba su peso militar en la región a través del Plan Colombia.

La preocupación brasileña por la injerencia estadounidense quedó plasmada en el simbólico hecho de que como reacción a la visita de Clinton a Colombia para impulsar el Plan Colombia en agosto de 2000 (Agencia EFE, 2000 agosto 5), Cardoso convocó en Brasilia la primera reunión de presidentes suramericanos, en la que se expuso la idea de crear una organización llamada Área de Libre Comercio de Suramérica (ALCSA), como alternativa regional al ALCA (Gudynas, 2006, p. 4), y la Iniciativa para la Integración de la Infraestructura Regional Suramericana (IIRSA). Valga aclarar que dicha reunión no fue vista con buenos ojos por parte de Estados Unidos (Moniz, 2006, p. 23). Tiempo después, el ALCSA tomaría el nombre de Unasur.

A partir de ese momento, el proceso suramericano ha tomado fuerza sin que esto implique que Estados Unidos haya quedado por fuera de la ecuación de poder regional. De cualquier forma, en este comienzo de siglo están cambiando las lógicas de la relación entre la superpotencia y la región respecto a lo que ocurría en el siglo pasado.

Recordemos que antes del fin de la bipolaridad, era factible que Estados Unidos argumentara que la Revolución Cubana, las intenciones autonomistas de Goulart y de Quadros en Brasil, o la elección de Allende como presidente en Chile, implicaban el avance de la 'amenaza comunista' sobre la América para los americanos de la Doctrina Monroe. La superpotencia, siguiendo su compromiso con el destino manifiesto y el deber civilizador que la guiaba, debía entonces intervenir para restablecer el orden y la paz del continente. Pero esta argumentación con la que se pretendía justificar dichas acciones, perdió su capacidad legitimadora cuando la Guerra Fría llegó a su fin. Otros discursos que identifican al narcotráfico y al terrorismo como los nuevos némesis, han intentado definir una nueva justificación para la intervención de Estados Unidos en el sur del continente, pero aunque no se puede negar que hasta cierto punto han cumplido con dicho objetivo, no lo han hecho con la misma eficiencia de la 'amenaza comunista'.

Tanto el narcotráfico como el terrorismo como ejes de la agenda entre el norte y el sur del continente, implican que el epicentro del relacionamiento sea la seguridad. Por eso, en la medida en que los acontecimientos de comienzos del siglo XXI fueron dirigiendo la atención de la superpotencia en materia de seguridad a otras latitudes, las relaciones entre Estados Unidos y Latinoamérica perdieron intensidad. Por un lado, la emergencia de China como un poder significativo a nivel global y los retos que eso conlleva para la hegemonía estadounidense, redundó en que el continente asiático fuera considerado como una prioridad geográfica. Por otro lado, los acontecimientos del 11 de septiembre de 2001 hicieron que Medio Oriente escalara posiciones en la lista de prioridades del 
país del norte y que dichas latitudes concentraran la atención del mismo en asuntos de seguridad. Y al desplazarse la atención en temas de seguridad hacia el otro lado del Pacífico, buena parte del contenido de la relación entre el norte y el sur de América se debilitó. Mientras más se hablaba del terrorismo en otro continente, menos aparecía América Latina en la agenda estadounidense (Hirst, 2011, p. 35).

\section{La Colombia panamericana}

Salvo algunos momentos particulares de su historia, Colombia ha sido un país claramente abocado a la concepción del espacio panamericano. De hecho, si hay que señalar un rasgo predominante en la política exterior del país, es su tradicional alineamiento con Estados Unidos, que incluso desde el periodo presidencial de Marco Fidel Suarez entre 1918 y 1921, recibe el nombre de Respice Polum (Tickner, 2007, p. 91). La mayoría de los gobiernos han sido claramente pro-estadounidenses y las élites, tanto económicas como políticas, se han sentido siempre muy cómodas con esta relación. En lo económico, durante prácticamente toda la historia republicana del país, Estados Unidos ha sido el principal socio comercial y foco de la política económica exterior. En lo político, Colombia ha dado juicioso cumplimiento a las recomendaciones hechas desde Washington enmarcadas en la Alianza para el Progreso, las certificaciones de lucha contra las drogas o el Plan Colombia, buscando obtener ciertos réditos en su relación con la superpotencia (Betancourt, 2012b, p. 312).

Recientemente, la relación con la potencia se enfocó en la firma de un TLC bilateral en lo económico y en problemáticas relacionadas con el narcotráfico y la seguridad en lo político, siendo estos, temas que han primado en la agenda a pesar de que por lo sensibles que resultan para el vecindario, han sido desencadenantes de un deterioro del buen entendimiento con los vecinos. Durante los últimos años, el país se distanció bastante de su entorno cercano y especialmente durante la presidencia de Álvaro Uribe, la alineación con la potencia del norte se fortaleció en detrimento de las relaciones con el vecindario.

Así, el siglo XXI comenzó con una Colombia avocada hacia el norte del continente. No solo fue el hecho concreto del Plan Colombia, sino también un momento político en el que mientras buena parte de los gobiernos suramericanos daban un 'giro a la izquierda' y asumían una voluntad autonomista frente a la principal potencia del mundo (Ramírez, 2007, p. 127), el país fue gobernado por el que fuera probablemente el mandatario más inclinado hacia la derecha del espectro político en las últimas décadas en el país.

Contrario a la mencionada voluntad autonomista de la región, el presidente Uribe buscaba un mayor alineamiento con Estados Unidos (Pastrana y Vera, 2012c, p. 57). También en contravía de la tendencia en el sur del continente de diversificar la agenda internacional y tratar temas como la participación en las organizaciones de gobernanza global y regional, la integración, el fortalecimiento comercial y el desarrollo de 
infraestructura, en Colombia la agenda internacional fue monopolizada por el asunto de la seguridad interna (Pastrana, 2011a, p. 75).

Sin embargo, algunos cambios se presentaron en Colombia y en la región cuando Juan Manuel Santos llegó a la presidencia. Si bien Santos en su campaña prometía darle continuidad a las políticas de su antecesor, pronto se evidenció un distanciamiento frente al mismo (Pastrana y Vera, 2012c, p. 58). Desde el principio de su gobierno, empezó a buscar la reconciliación con los vecinos, el acomodo de Colombia al espacio latinoamericano y contrario al bilateralismo precedente, privilegió el multilateralismo. No se produce una renuncia a los objetivos previos de la política exterior y Estados Unidos sigue siendo una prioridad y la seguridad un tema importante, pero ya no exclusivo ni excluyente de nuevas alianzas como la que se empezó a tejer con Brasil (Pastrana, 2012, p. 4).

Esto ha venido acompañado de cambios en el orden global que está en pleno proceso de transformación. En primer lugar, la clásica división del mundo entre desarrollado y subdesarrollado, en la que los países pertenecientes a la primera parte de la dicotomía eran responsables de un altísimo porcentaje de la economía planetaria, se ha venido transformando. Incluso en el año 2000, no muy distante de nuestro tiempo, el G7 de países desarrollados era responsable de 72\% del PIB mundial, mientras que para $2012 \mathrm{su}$ participación ya se había reducido a 53\% a favor de las economías emergentes (Pastrana y Vera, 2012b, p. 136). Para Colombia, este cambio se ha traducido en que sea considerado como una promesa económica para el futuro y que en consecuencia, haya sido catalogado como un CIVETS ${ }^{1}$. El simple acrónimo, le dio al país una gran visibilidad como potencial receptor de inversión extranjera directa, y esto implicó un cambio en la propia percepción (Guerra-Barón, 2012, p. 392).

Colombia asumió dicho acrónimo como la responsabilidad de que debe dejar de ser visto en el contexto internacional como un país problema y receptor de ayuda y que está en capacidad de convertirse en un actor relevante y con capacidad de autoagenciamiento. Esto definitivamente influyó en que el aislacionismo del país respecto a la región que se vio en los últimos años, le haya dado paso a un rol nacional más activo y con voluntad de liderazgo regional, así como una política avocada al multilateralismo. De hecho, parte del objetivo de tener ese papel más activo se corresponde con el interés de dejar de ser visto como un país hostil en contravía de los procesos regionales y así, constituirse en socio de países como Brasil y Chile que se han convertido en emisores de inversión extranjera directa (IED).

El interés de Colombia por entrar a ser parte de la OCDE (Organización para la Cooperación y el Desarrollo Económico), organización de los 34 países más ricos y

\footnotetext{
${ }^{1}$ La Economist Intelligence Unit definió a Colombia, Indonesia, Vietnam, Egipto, Turquía y Sudáfrica como CIVETS, que tienen un común denominador al ser países emergentes con características que los hacen económicamente importantes y atractivos.
} 
oferentes de ayuda internacional, encaja en este propósito. De la misma forma, los esfuerzos por proyectar una imagen de país que no requiere del favor de otros para tratar los asuntos propios puede apuntar a la definición de una relación con Estados Unidos de socios más que de subordinación (Pastrana, 2012, p. 21).

Por otra parte, entre las transformaciones globales no se puede olvidar el auge de las economías del Asia-Pacifico que como en ninguna otra región del mundo, han aumentado su participación en la economía planetaria. Colombia, como cualquier país interesado en su bienestar económico, ha empezado a preocuparse por el incremento de sus vínculos económicos transpacíficos y no solo con el Atlántico Norte como había sido su objetivo histórico. Lo anterior ha motivado que le haya apostado a apoyarse en Latinoamérica para alcanzar sus objetivos en Asia-Pacifico, manifestándose esto, por ejemplo, en el impulso que se le ha dado a la Alianza del Pacífico desarrollada como estrategia de cooperación con México, Perú y Chile, y crecientemente, con otros países de esta cuenca.

\section{Unas nuevas condiciones materiales}

Además de la geopolítica planetaria, las capacidades materiales de Suramérica también se han modificado. Después de la primera mitad de la década de 1970, cuando se presentó el embargo petrolero de la OPEP, el precio internacional del petróleo se ha mantenido bastante elevado. Mientras que en los años sesenta el barril de petróleo rondaba los US\$20, en los años setenta alcanzó los US\$100 y se ha mantenido cercano a ese valor hasta la actualidad. Y más allá del elevado valor de los hidrocarburos, en general el precio de las materias primas ha registrado un considerable repunte impulsado por el acelerado crecimiento de China e India, entre otros factores.

Ahora bien, siendo importante el incremento de los ingresos, es posiblemente más relevante analizar el origen de los mismos. Durante buena parte del siglo pasado los intereses de la superpotencia en Suramérica en materia económica eran prácticamente los únicos que influían en la región y en todo caso los que tenían más peso, y asimismo el principal objetivo de los intereses económicos del sur del continente se enfocaban en Estados Unidos. Pero más recientemente, el panorama se ha ampliado y además de Estados Unidos, potencias emergentes como China, Rusia y el mismo Brasil han empezado a poner sus ojos en Suramérica y viceversa (Tokatlian, 2009). Si a esto le sumamos que desde 2007 los Estados centrales han atravesado una fuerte crisis económica, podemos identificar un panorama en el que el binomio Estados Unidos-Suramérica ya no es la única posibilidad de relacionamiento ni el determinante solitario de los procesos regionales.

Esto ha propiciado una importante diversificación de los destinos comerciales, lo que tiene grandes implicaciones. La consecuencia de que Estados Unidos monopolizara los intereses comerciales era que las élites económicas y políticas de los países suramericanos se sentían más familiarizadas y atraídas por la superpotencia. El hecho 
de que se hayan diversificado geográficamente los intereses económicos de estos países y que se construyan lazos extraregionales con Europa, Asia, y especialmente, con China, así como intrarregionales, deriva en una disolución del poder relativo de Estados Unidos en la región (Sorj y Fausto, 2011, p. 5).

Dicha diversificación resulta palpable al observar la evolución delos vínculos comerciales de Suramérica con varios de sus socios en la primera década del siglo XXI: Estados Unidos pasó de representar 26,49\% de las exportaciones suramericanas en el año 2000 a 18,15\% diez años después. Europa por su parte pasó de representar 17,3\% a 14,22\% en el mismo periodo. Como se ve, el relacionamiento comercial con las potencias tradicionales tiene una tendencia a la baja y hoy en día, son menos importantes que Asia y el Pacífico, que pasaron de representar 8,98\% de las exportaciones suramericanas en 2000 a 18,42\% en 2010; y que el subcontinente latinoamericano que ha alcanzado el 34,64\% en 2010 (CEPAL, 2011).

Si bien Estados Unidos sigue siendo importante tanto para la política interna como externa de los países suramericanos, la diversificación comercial ha propiciado que las élites no miren exclusivamente hacia el norte, sino que amplíen su visión geográfica y que miren hacia otras latitudes con buenos ojos. Países como Brasil, Chile, y Colombia en el periodo presidencial de Santos, han comprendido que es importante tener buenas relaciones con la superpotencia, pero que esto no se puede lograr sacrificando las buenas relaciones con otros socios que cada vez son más importantes. Esto permite argumentar que el fuerte bilateralismo que llevó a que países como Colombia fueran pasivos receptores de la Doctrina Monroe durante el siglo XX, se ha debilitado en favor de un multilateralismo que amplía el abanico de posibilidades, permitiendo una mayor autonomía.

Aun así, se debe considerar que la actitud confrontacional de los países del ALBA frente a la potencia del norte fue un tema de preocupación para Brasil porque al despertar la incomodidad de la superpotencia podía convertir a la región nuevamente en un espacio de intervención bajo el argumento de ser fuente de inestabilidad y una amenaza para la seguridad del norte (Ramírez, 2011, p. 127). Es por esto que el liderazgo de Brasil se ha concentrado en mantener el margen de autonomía ganado apaciguando a los Estados más confrontacionales para mantener un buen entendimiento con la superpotencia. El proyecto de construcción de Suramérica liderado por Brasil no es un antagonista de Estados Unidos, sino una prudente alternativa y en la medida en que desde la llegada de Santos al gobierno, Colombia lo ha ido entendiendo de esta manera, se ha sentido más cómoda y ha empezado a desarrollar un papel más activo en la región.

\section{Colombia en la Suramérica brasileña}

Brasil no puede obviar la importancia de Colombia en la consolidación de los procesos regionales. De hecho, incluso antes del acercamiento que tuvo Colombia en su más reciente periodo presidencial, el país ya era importante para Brasil porque lo consideraba la 
puerta de entrada de Estados Unidos a la región. La actitud confrontacional del gobierno venezolano frente al hegemón del norte, generaba una preocupación en la superpotencia que en consecuencia intentaba estrechar los lazos con una Colombia bastante receptiva a que eso ocurriera y dispuesta a proporcionar incluso la posibilidad de que Estados Unidos tuviera presencia militar en el espacio suramericano (Hirst, 2004, p. 119).

Por lo anterior, si bien las relaciones colombo-brasileñas en aquel periodo no llegaron a ser particularmente cooperativas, Lula e Itamaraty procuraron intensificar el relacionamiento entre estos dos países al punto de ofrecerse como mediador en un posible proceso de negociación entre gobierno y guerrillas colombianas. En suma, la idea era acercarse a Colombia, volverse mediador en la relación entre esta y Venezuela y en consecuencia, mantener alejado a Estados Unidos evitando que este último fuera el intermediario (Ramírez, 2007, p. 149).

El asunto era crucial para Brasil. Colombia y el gigante suramericano comparten una gran frontera en la Amazonía, selva que constituye parte central de la identidad brasileña y eje estratégico de su futuro. Brasil no se siente nada cómodo teniendo en su frontera norte una puerta abierta y permisiva a que la superpotencia tenga influencia en la Amazonía, y dado que en la tradición colombiana problemáticas como su conflicto armado interno, el narcotráfico, o diferencias con los vecinos tienden a tratarse mirando hacia el norte, Colombia se convirtió en parte estratégica de su política exterior. Por su parte, Colombia, poco interesada en ese momento en participar del proyecto de construcción de Suramérica, estableció un acuerdo militar con Estados Unidos cuyo resultado sería trasladar la presencia militar que la potencia tenía en la base de Manta, Ecuador, a suelo propio (Londoño, 2011, p. 235).

Como bien lo afirma Carvajal (2011, p. 282), el acuerdo militar pretendía ser un instrumento de disuasión frente a los vecinos, particularmente Venezuela y Brasil, que en años recientes venían aumentando su capacidad militar. Al final, la Corte Constitucional de Colombia declaró la inconstitucionalidad de dicho acuerdo militar y este no llegó a materializarse, pero por ejemplo, ha sido muy difícil dinamizar los acuerdos SIVAMSIPAM para controlar el espacio amazónico. Si bien Colombia ha dicho que esto se debe a los altos costos que implicaría, para Brasil la explicación se encuentra en la presión de Washington sobre Colombia. (Ramírez, 2007, p. 155).

Ramírez (2007, p. 163) reafirma el hecho de que Colombia iba en contravía del proceso suramericano y que abiertamente intentaba incluir a Estados Unidos en un espacio que pretendía delimitarse excluyéndolo precisamente para evitar las dificultades que devienen de habitar el mismo espacio de una superpotencia hegemónica. Además, la interdependencia suramericana que pretendía intensificar Brasil mediante acciones como la ampliación del Mercosur y su acercamiento a la CAN entre otros (Lafer, 2002, p. 63), se veía afectada por la permanente tensión que generaba Colombia. Nótese que 
este contrapunteo lleno de tensiones y desacuerdos no necesariamente conduce al desplome del proyecto brasileño.

En este caso, el desafío que representaba la situación para Brasil se conjugó en la creación del Consejo de Defensa Suramericano (CDS) que justamente pretendía copar el espacio que podría ocupar Estados Unidos dados los vacios en temas de seguridad de países como Colombia (Arroyave, 2012, p. 265).

En suma, se evidencia que el tradicional contrapunteo entre el Latioamericanísmo y el Panamericanismo se resolvió casi siempre a favor de este último. Sin embargo, sin obviar las transformaciones globales y regionales que debilitan el sustento del Monroísmo y dado el liderazgo de Brasil y su reinterpretación del Latinoamericanísmo, moldeado ahora como Suramericanísmo, ha surgido una alternativa al Panamericanismo.

\section{Estados Unidos frente a la nueva Suramérica}

De momento se ha mostrado la forma en que Suramérica percibe a Estados Unidos, pero dado el lugar que ocupa la superpotencia en la jerarquía de poder mundial, puede resultar tanto o más significativa la forma en que esta percibe a la región en construcción. Aunque aquí se habla de procesos y no de hechos consumados, es posible identificar algunas tendencias. La National Security Strategy de mayo de 2010, emitida durante el primer gobierno de Barack Obama, no pasa de mencionar de forma genérica a Latinoamérica en un párrafo en el que menciona que esta región, junto con África y el Pacífico, ofrecen interesantes opciones de relacionamiento (The White House, 2010, p. 8). Pero además de este comentario general, no parece haber una estrategia clara de aproximación al sur del continente ni unos objetivos claros y el tradicional hegemón parece ser apenas un observador relativamente pasivo del proceso de construcción de Suramérica. Desde la presidencia de Clinton y específicamente tras el fracaso del ALCA, no parece haber un horizonte claro.

No en vano, incluso una de las relaciones bilaterales más estrechas que era la de Estados Unidos con Colombia, ha estado definida por los vaivenes de algunas coyunturas o por la afinidad entre ciertos mandatarios y no por unos objetivos claros enmarcados en un plan definido (Sánchez y Monroy, 2012, p. 325). A parte de la afinidad entre George Bush y Álvaro Uribe y las diferencias entre estos y el gobierno venezolano que marcaban los referentes de la relación entre el norte y el sur, no hubo, más allá de lo pasional, una agenda estructurada. El comienzo del gobierno de Obama hizo pensar que esto podía cambiar, pero luego se hizo evidente que en realidad el asunto no dependía solo de un cambio de gobernante. Ya desde hace tiempo la superpotencia tiene dificultades para comprender el proceso que está teniendo lugar en Suramérica (Grabendorf, 2010, p. 159). Y si bien en parte esto ha posibilitado el aumento de la autonomía de la que se habló anteriormente, implica también que no sea fácil definir cuál será la actitud de Estados Unidos frente a 
Suramérica en algunos años. Al igual que la región, la percepción de la superpotencia se encuentra en construcción y aun no tiene claro si apoya el proceso o se le opone.

En algunas ocasiones, los acontecimientos que han tenido lugar en el sur del continente le han generado incomodidad. Por ejemplo, cuando fracasó el proyecto del ALCA la potencia regional asumió una posición que generó preocupación en la superpotencia (Roett, 2007, p. 57). Por un lado, se puso en evidencia que era posible contrarrestar el poder de Estados Unidos para imponerse en Suramérica si esta, bajo el liderazgo de Brasil, era capaz de producir un consenso y unos objetivos comunes que permitieran una impugnación contra la superpotencia (Pastrana y Vera, 2012a, p. 619). Por otro lado, le dio la confianza a Brasil de que podía actuar como potencia líder regional a partir del respaldo a uno de los principios básicos de su identidad internacional que es el de propender por la cercanía entre los pueblos latinoamericanos (Lafer, 2002, p. 61).

Estados Unidos notó en esa oportunidad que Brasil no solo estaba estrechando los lazos con sus vecinos, sino que tenía como propósito establecer unos límites a la capacidad de acción de la potencia del norte en el sur del continente. En un artículo de 2001, Henry Kissinger manifestó que su país debía poner atención a lo que estaba ocurriendo en Suramérica en tanto que Brasil estaba formando un club en el que el requisito para participar era "no ser Estados Unidos" (Kissinger, 2001, p. 159).

El multilateralismo de Brasil salió bien librado en su disputa contra el unilateralismo estadounidense en las negociaciones del ALCA. De este hecho surgió Unasur, que le hace contrapeso a la OEA y por lo tanto al sistema interamericano. Este sistema alternativo, además, excluye deliberadamente a Estados Unidos y le da cabida a países como Venezuela, Ecuador y Bolivia que son fuertes críticos de la superpotencia. Suramérica, por si fuera poco, desdibuja a Las Américas, a la Panamérica y a la Interamérica, espacios que definían la zona de influencia tradicional de la superpotencia. Teniendo todo esto en cuenta, ¿́puede la superpotencia tolerar la construcción de Suramérica y el liderazgo de Brasil?

Estos hechos, que seguramente serían impensables en un contexto de Guerra Fría, se han encontrado con la inconformidad y sin embargo inacción de la máxima potencia mundial. Tampoco ha habido mayor reacción de Estados Unidos ante hechos como que hayan llegado a la región varios gobernantes con un estilo bastante confrontacional; que se hayan planteado posiciones críticas sobre la política antidrogas estadounidense e incluso propuestas para que esta sea reformulada, llegando a mencionar el tema de la legalización, siendo estas, discusiones en las que hasta Colombia ha participado, y en las que Uruguay ya ha dado pasos gigantes que van más allá de la mera discusión; o que Ecuador haya sacado la base militar estadounidense en Manta; o que en Paraguay Alejandro Hamed Franco, defensor de la causa palestina, investigado por agencias de 
seguridad estadounidenses, haya sido nombrado ministro de relaciones exteriores. Ante la pasividad de Estados Unidos en temas aparentemente tan sensibles, es factible indagar si la Doctrina Monroe ha llegado a su fin (Tokatlian, 2009).

Por otra parte, no todo en la construcción de Suramérica es contraproducente para la superpotencia, que de hecho considera valioso el papel de Brasil como un estabilizador de la región que le aligera una carga en un momento en el que su atención está puesta en otras regiones del mundo. El gigante del sur puede cubrir el vacío que deja la ausencia de una estrategia clara de Estados Unidos hacia la región y eso es algo que le resulta cómodo y económico a la potencia del norte, que de hecho, ha dejado saber que apoya a Brasil y su liderazgo, e incluso a Unasur, a pesar de ser consciente de que esto limita a la OEA y al sistema interamericano (Hakim, 2011, p. 17 y 18).

Cuando se constituyó el Consejo de Defensa Suramericano (CDS) Brasil se lo informó a Estados Unidos indicándole cuáles eran sus propósitos, a lo que Estados Unidos respondió dejando ver su beneplácito (Sorj y Fausto, 2013, p. 52). La misma Casa Blanca se ha expresado en el sentido de respaldar el liderazgo que viene desplegando Brasil (The White House, 2010, p. 44).

\section{La participación colombiana en el proyecto suramericano}

Las organizaciones de cooperación e integración en Latinoamérica no son una particularidad del proceso de suramericanización. Desde ya hace varias décadas, el subcontinente ha visto aparecer -y desaparecer- varias organizaciones, al punto que a la fecha, existe una amplia oferta de espacios de participación multilateral, entre los que es posible identificar al menos tres conjuntos de proyectos de cooperación e integración: el del Arco Pacífico, el del ALBA, y el suramericano.

El primero de estos, llamado de la Alianza del Pacífico, es protagonizado por países que pertenecen a esta cuenca oceánica y que geográficamente se encuentran entre Chile en el sur y México en el norte, incluida Colombia. Este escenario privilegia la firma de tratados de libre comercio y la inserción en Asia-Pacífico. En ella predomina la cercanía con Estados Unidos y el distanciamiento de este país no es un objetivo. El segundo grupo es el del ALBA, en el que además de Venezuela -que ejerce como líder-participan los Estados que como Bolivia, Nicaragua y Ecuador -este último con creciente protagonismo-,desarrollan políticas rupturistas, son críticos de la hegemonía estadounidense y escépticos respecto al libre comercio.

Finalmente, se identifica el grupo suramericano, que bajo el claro liderazgo de Brasil, persigue una autonomía que no se define en contraposición con Estados Unidos, que mantiene buenas relaciones con la superpotencia aunque intenta limitar su influencia, comulga con la idea del libre comercio aunque definiéndolo como un medio para alcanzar el desarrollo y la redistribución y que tiene su base organizacional en Unasur y Mercosur. 
No es sorpresa que por afinidad ideológica, Colombia se sienta bastante cómoda dentro de las iniciativas del Arco Pacífico y que le preste especial atención a la Alianza del Pacífico de reciente constitución o a iniciativas como el Foro de Cooperación de América Latina-Asia Pacífico (FOCALAE) ${ }^{2}$. Si bien en esta vertiente del multilateralismo se han desarrollado dinámicas institucionales, su cuerpo organizacional no es el más consolidado dado que el tipo de objetivos que se persiguen no pretenden ir más allá de establecer sinergias de coordinación intergubernamentales orientadas hacia objetivos comerciales.

Pese al gran interés que Colombia ha puesto en la Alianza del Pacífico, no desconoce el potencial del proyecto suramericano como espacio en el que se puede desarrollar un rol regional activo y propositivo. La perspectiva ideológica de este espacio genera menos resistencia que la de los dos anteriores y por ello sirve de escenario de convergencia de los países del ALBA y los del Pacífico, no entra en conflicto con Estados Unidos -lo cual seguramente sería inaceptable para Colombia-, y tiene importantes dinámicas institucionales - cada vez más dotadas de un cuerpo organizacional- que contemplan una agenda amplia.

De momento, la toma de decisiones en la definición del espacio suramericano recae en Brasil que se ha resistido a distribuir en el vecindario tales atributos. Es por eso que las organizaciones existentes actualmente privilegian la cooperación y no tanto la integración, pues esta ultima implicaría ceder soberanía y avanzar hacia formas compartidas de la misma. Sin embargo, la posibilidad con la que cuentan las potencias secundarias de impugnar el poder brasileño puede llevar a que en el futuro sea necesario tanto para Brasil como para Colombia, Argentina, Chile y Venezuela profundizar el multilateralismo, realizar concesiones en materia de soberanía y desarrollar patrimonios comunes que incluso podrían derivar en integración.

\section{Unasur: el cuerpo suramericano}

La Unasur es la fase actual de un proceso que nació en las Cumbres de Presidentes Suramericanos convocadas por Brasil y de las propuestas del Área de Libre Comercio de Suramérica formulada por Fernando Henrique Cardoso (Gudynas, 2006, p. 4), que implicó un hito en la reingeniería al Latinoamericanísmo.

Es así como el nacimiento de Unasur define la aparición de Suramérica como parcial heredera del Latinoamericanísmo y en consecuencia como alternativa al panamericanismo. Este organismo, que en su proceso de creación delimitó el nuevo espacio, originó que por primera vez en la historia hubiera un escenario de encuentro exclusivo del sur del continente, llegando a tener a la fecha una concepción política y económica lo suficientemente amplia como para que quepan e incluso dialoguen países tan divergentes

\footnotetext{
${ }^{2}$ El Foro de Cooperación de América Latina-Asia del Este, es una iniciativa que busca estrechar los vínculos entre las dos regiones apuntando hacia una inserción económica.
} 
en temas ideológicos como Colombia y Venezuela. Unasur no es uno más de los muchos organismos multilaterales que se han creado en el subcontinente, pues si bien aún se encuentra en una etapa temprana, ya es una experiencia singular y prometedora en el contexto regional (Amorim, 2009, p. 14).

De hecho, en la idea de Lula da Silva, Unasur debía servir también como escenario de encuentro y concertación política, cultural y social, lo que implicaba ubicarse frente al esfuerzo de crear unos mínimos comunes, unos valores compartidos, unas intenciones conjuntas, en suma, una identidad suramericana moldeada por el liderazgo de Brasil pero en la que los demás Estados son participes. La tarea no era fácil y está lejos de ser completada, pero es un paso importante.

A pesar de lo reciente que es el organismo y sin obviar que está lejos de consolidarse, ha ganado una fuerza relevante en comparación con cualquiera de sus pares regionales vigentes. La OEA, emblema del panamericanismo y tradicional escenario de encuentro entre los países del continente, se ha debilitado en el contexto de transformaciones globales ya mencionado, y ese lugar en el sur del continente, lo viene tomando Unasur. Se contrapone al sistema interamericano en la medida en que en este reside el Monroísmo y la influencia estadounidense es máxima, mientras que en el organismo del sur, está contenida la idea de que los asuntos suramericanos los debe resolver Suramérica.

En algunas ocasiones esta orientación del organismo se ha puesto a prueba, pues en él se han tratado asuntos álgidos como la inestabilidad política de Bolivia, el intento de golpe de Estado en Ecuador, la situación política de Paraguay, las tensiones entre Venezuela y Colombia, o la preocupación del vecindario cuando esta negoció el ya mencionado acuerdo militar con Estados Unidos. En todas estas ocasiones, con mayor o menor éxito, fue Suramérica la que abordó y resolvió sus propios asuntos. Desde luego, además de los esfuerzos de Suramérica en general, las temáticas abordadas en Unasur tienen en común que engloban las preocupaciones en materia de seguridad de Brasil, siendo esa una de las razones que más comprometen al gigante del sur con el organismo (Herrera, 2011, p. 485).

Lo anterior, insistamos en ello, no implica que se trate de una organización consolidada ni que de momento esté siendo vector de la integración suramericana. Como sostiene Haas (1970), integración es el concepto que describe un proceso mediante el cual los Estados renuncian a la plena soberanía, transfiriendo algunas de sus funciones específicas a organizaciones supranacionales de modo tal que se asocian con sus vecinos y crean espacios comunes en los que se pretende sacar adelante iniciativas que redundan en beneficios para la región en general, a la vez que adquieren técnicas de resolución de conflictos mutuos.

Unasur, como la mayoría de organizaciones multilaterales que han nacido en la región, apenas pueden ser consideradas como de cooperación dado que no cumplen con las anteriores características, es decir, son mecanismos de coordinación política alrededor de ciertos lineamientos para perseguir intergubernamentalmente objetivos comunes 
(Keohane y Nye, 1988). Aun teniendo una agenda amplia e influyente, de momento no es más que un espacio de cooperación y nada ha avanzado en la construcción de la supranacionalidad que exige la integración. Hay una clara renuencia de los países de la región y particularmente de Brasil, a ceder soberanía a favor de organismos supranacionales que constriñan su autonomía y que le otorguen poder de decisión a los demás sobre sus propias políticas.

En definitiva, Colombia ha asumido una posición activa en Unasur, pero no por ello renuncia a otros espacios como la Alianza del Pacífico. Además, esta organización tiene un peso importante pero en el último tiempo no ha evolucionado con el mismo dinamismo que tuvo en sus primeros momentos. Eso confirma la idea que ya se ha esbozado de que Colombia puede acercarse al espacio suramericano, tener allí un rol activo, pero que el compromiso no es irrestricto y depende bastante de la forma en que Brasil direccione el proceso.

\section{Mercosur: el corazón de Suramérica}

Mercosur es otra de las organizaciones que encabeza el espacio suramericano. También de ingeniería brasileña, Itamaraty lo concibe como el núcleo de su proyecto, siendo Unasur la cubierta que lo envuelve (Pastrana, 2011b, p. 14). Esta organización surge y evoluciona muy de la mano de los vaivenes de la relación entre Brasil y Argentina, y de los ya tratados eventos de 1985 en los que los acuerdos de Foz de Iguazú generaron un nivel de confianza entre los dos países del cono sur que finalmente se materializó en esta organización.

La organización cobró gran importancia al enfrentarse con expresiones recientes del Monroísmo como lo pueden ser la propuesta del ALCA. Mercosur implicaba que el libre comercio tenía una alternativa menos peligrosa en términos de lo que significaba una negociación comercial asimétrica con la potencia del norte. El organismo del sur fue entonces el escenario donde se gestó la creación de un bloque de países que establecieran una posición conjunta para encontrar un lugar más favorable en la negociación del ALCA (Gudynas, 2006, p. 4) y asimismo, fue el escenario en el que Brasil comprendió la utilidad de generar un espacio regional (Bermúdez, 2011).

Previa a la concepción de una única organización que abarcara a Suramérica, Brasil pensó en utilizar a Mercosur como plataforma para generar este espacio, en una alianza en la que con la CAN, se unieran el norte y el sur del subcontinente. Al final esto no ocurrió y ambos sistemas siguieron existiendo por separado, pero más recientemente ha sido el propio Mercosur el que se ha expandido hasta alcanzar una cobertura casi suramericana, siendo esta la piedra angular del proceso de suramericanización que inició la potencia regional (Spektor, 2011, p. 161).

De la mano de Unasur, Mercosur es hoy, pese a la reticencia de Brasil a ceder soberanía y a una serie de problemas que la aquejan, la punta de lanza que puede desencadenar 
un eventual proceso de integración. Además de avanzar en la consolidación de una zona de libre circulación de bienes, servicios, factores productivos y personas, ha intentado ser centro de concreción de unos 'valores del Sur' (Bermúdez, 2011, p. 211).

La propuesta inicial de generar un acercamiento entre Mercosur y la CAN, que habría posibilitado una negociación importante entre estas dos organizaciones, parece estar archivada. La salida de Venezuela de la CAN y su ingreso al Mercosur como Estado miembro no parece dictar una tendencia que en el corto plazo vaya a ser seguida por Colombia, que ya ejerce como Estado asociado, pero dado a que su modelo de relacionamiento es más parecido al chileno que al brasileño o al venezolano, es de esperar que no intente una pertenencia total al organismo, pues esto implicaría unas restricciones que podrían chocar con otros objetivos de Colombia como el AIP y el desarrollo del TLC con Estados Unidos.

$\mathrm{Al}$ igual que con Unasur, Colombia se ha aproximado a Mercosur pero el compromiso no es irrestricto y no se superpone a otros objetivos políticos y comerciales. Y de cualquier forma, el organismo actual no es tan ambicioso como aquel que era guiado por Lula da Silva y Néstor Kirchner, por lo que aunque el mercado del Cono Sur sigue siendo atractivo para Colombia, el poco dinamismo de Mercosur le resta algo de interés a tener una participación más activa (Sorj y Fausto, 2013, p. 58).

Esto no significa que para Colombia deje de ser estratégico apostarle a un mayor intercambio con el espacio comercial que cobija Mercosur. La economía planetaria se encuentra en proceso de transición y pese al crecimiento económico que se viene presentando en la mayoría de los países suramericanos, sus economías se están reprimarizando. Colombia, por ejemplo, cuya industria representaba en el año 2002 60,22\% del total de sus exportaciones, bajó a un alarmante 40,87\% en solo diez años (DANE, 2012). Ante esta realidad, el valor del comercio intrarregional no puede ser desechado. Mientras buena parte de las exportaciones industriales del país se dirige a los países de la región con un grado de desarrollo similar o inferior al colombiano, las exportaciones predominantes a los países industrializados provienen del sector primario extractivo (Salcedo, 2011, p. 343).

\section{Lo propiamente suramericano}

En junio de 2012, después de que el presidente paraguayo Fernando Lugo fuera destituido de su cargo por el Congreso de una forma que se leyó como anticonstitucional, Unasur y Mercosur suspendieron la participación de dicho país en estos escenarios (Telesur, 2012). Una actitud similar había sido tomada por Unasur en noviembre de 2010 cuando la inestabilidad política de Ecuador amenazó con romper el orden constitucional del país y darle un golpe de estado al presidente Correa. Rápidamente, el organismo se reunió y anunció que no aceptaría que fuera ese el desenlace de la situación y pidió que el presidente constitucional se mantuviera en el poder. 
Este comportamiento se explica por el Compromiso con la Democracia que se anexó como un protocolo adicional en noviembre de 2010 al Tratado de Brasilia. El primer artículo de ese protocolo contempla una serie de medidas que se ejecutarán si en alguno de los países miembro se produce una ruptura del orden constitucional y democrático que ponga en peligro el ejercicio legítimo del poder. Dicho protocolo, hizo extensiva la Declaración de La Moneda de 2008 en la que el subcontinente se comprometía con la democracia a grado tal que afirmaba que los problemas que afecten la democracia de un país, se considerarían un problema para toda la región (Arroyave, 2012, p. 247).

Lo anterior no es de extrañar dentro de una institucionalidad liderada por Brasil. Este país ha reconocido que durante el periodo de la Guerra Fría, Estados Unidos optó por estimular y apoyar las dictaduras y fenómenos anticonstitucionales para influir en Latinoamérica. La potencia regional ha asumido que los pobladores de la región son capaces de agenciar su propio destino y que eso solo será posible si participan en las decisiones de sus respectivos gobiernos por la vía de la democracia y que eventos como golpes de estado, atentan contra esta posibilidad. En virtud de lo anterior, es entendible que organizaciones como Unasur o Mercosur contengan clausulas democráticas que sancionen firmemente las interrupciones de los ordenes democráticos (Lafer, 2002).

El hecho de que, aunque entendida en un sentido bastante laxo, Suramérica opte por la democracia y por la economía de mercado, hace que Colombia se sienta cómoda en este espacio y que esté dispuesta a participar en él.

$\mathrm{Al}$ respecto, Bermúdez (2011, p. 211) sostiene que particularmente Mercosur se ha venido consolidando como el centro de una comunidad de valores que le da una identidad propia al espacio delimitado. Estos valores son, según este autor, la defensa de la democracia, de los derechos humanos, de las libertades fundamentales, la protección del medio ambiente y el desarrollo sostenible. La misma organización está comprometida con sus propios estandartes, que son la seguridad jurídica, la lucha contra la pobreza y el desarrollo económico y social equitativo. No en vano este sistema ha desarrollado el Mecanismo de Consulta y Concertación que a menudo expresa posiciones comunes que exceden lo propiamente comercial y económico (Weisstaub, 2006, p. 21). Suramérica se asume entonces como un escenario autónomo que busca desprenderse de la excesiva injerencia de actores externos, especialmente Estados Unidos, pero que sin embargo mantiene una buena relación con estos y definitivamente, no intenta ser confrontacional. La declaración de Bariloche de 2009, por ejemplo, reclama a Suramérica como una zona de paz que debe evitar la conflictividad interna y la presencia de tropas extranjeras que pongan en peligro el buen trato y la soberanía de toda la región (Arroyave, 2012, p. 248).

Asimismo, no hay cuestionamientos de fondo al libre comercio, mientras que el interés en la inserción internacional es significativo, lo que distingue a este proceso de otros que tuvieron lugar en las décadas de 1960 y 1970. Sin embargo, la apropiación de esa forma 
de comercio e internacionalización no se conciben como un fin en sí mismo sino como un medio que es válido en la medida en que pueda producir crecimiento económico con equidad social. Finalmente, es un espacio que en la medida que se consolide, puede intentar incidir en la agenda internacional, llevando objetivos de elaboración propia.

Con el cambio en el patrón de comercio que Suramérica tiene con el mundo, se hace posible, más que en cualquier otro tiempo, ganar autonomía frente a Estados Unidos y volverse socia de sí misma. Sin lugar a dudas la potencia del norte sigue siendo importante, pero ya no puede monopolizar el horizonte de la voluntad política de los países del sur del continente. Contrario a esto, se vuelve más importante que nunca acudir al multilateralismo para mejorar las relaciones con Europa, Asia-Pacífico y definitivamente, con la propia Suramérica. Así, ha aparecido la oportunidad de apostarle a las relaciones con el mundo y no solo a una parte limitada de este continente.

Después del fracaso de las iniciativas de integración latinoamericana de las décadas de 1960 y 1970, la sensación de incapacidad de construir un destino propio llevó al subcontinente de vuelta a la amistad incondicional con Estados Unidos. La Doctrina Monroe parecía vigente a finales de la década de $1980^{3}$ y comienzos de la de 1990, cuando la desconfianza en los procesos de identidad latinoamericana hizo a buena parte de los países bastante receptivos a las propuestas estadounidenses. Prácticamente todos los Estados del subcontinente se vieron reformados a favor de las políticas neoliberales que de ninguna manera habían ayudado a concebir, pero que en ese momento de desencanto por las iniciativas propias, poco importaba. El nuevo Consenso de Washington era una nueva versión del “deber civilizador de intervenir en el Sur en caso de caos" del que hablaba Roosevelt.

Esta forma en la que comenzó el siglo XXI hace que resulte sorprendente que solo veinte años después la revista Foreign Affairs, en su ejemplar de mayo-junio de 2008, se haya preguntado: ¿Se perderá el control, particularmente, sobre el hemisferio sur? ¿Estamos perdiendo a América Latina? (Drekonja-Korna, 2011). Una pregunta consecuente sería: ¿estamos viendo el ocaso de la Doctrina Monroe?

No se pone en duda que Estados Unidos sigua siendo una superpotencia sin par y que ni siquiera necesita la aprobación del Consejo de Seguridad para declarar una guerra. Debe hacerse claridad sobre lo que se está planteando aquí: no es lo mismo afirmar que la Doctrina Monroe se encuentre en su ocaso (tesis aquí sostenida) y afirmar que estamos ante el declive de Estados Unidos como superpotencia, lo cual no sería preciso. Que este país siga teniendo hoy en día un poder incomparable, es algo que pocos dudan (Herrera,

\footnotetext{
${ }^{3}$ Desde algunas perspectivas, esto es polémico. Smith (1994) por ejemplo, considera que el fin de la Doctrina Monroe viene con el fin de la Guerra Fría, pues este episodio supuso el fin de las amenazas extracontinentales en la región.
} 
2012, p. 377). Pero de la efectividad del Monroísmo en el manejo de sus relaciones con el sur del continente, es más factible dudar.

Más allá de la transición hacia un mundo multipolar, hay en Suramérica una intención de tener un relacionamiento comercial geográficamente amplio, de producir cambios políticos, de romper los vínculos de obediencia y de ejercer autónomamente la soberanía. Por eso, a pesar del lento avance en el desarrollo de las organizaciones de gobernanza regional y de que en dicho espacio se hablen lenguajes políticos muy variados, hay unos referentes comunes como la Unasur, el Mercosur, el multilateralismo, la economía de mercado más o menos liberalizada y la democracia, que conllevan a que, aunque Suramérica sea parcialmente heredera del Latinoamericanísmo de los siglos anteriores, tenga unas formas de relacionarse con Estados Unidos y con el mundo más pragmáticas y viables que las de su predecesora.

Por lo tanto, es posible hablar del ocaso de la Doctrina Monroe, primero, en el sentido en que Suramérica no se reconoce a sí misma como el patio trasero de Estados Unidos; segundo, en tanto que las condiciones materiales son más favorables y permiten que esto sea así; tercero, que el sur del continente ha perdido relevancia en la agenda de seguridad estadounidense; y cuarto, que la nueva mentalidad es más propositiva y menos sumisa.

\section{Conclusiones}

El final de la Guerra Fría marcó el inicio de un periodo de transición entre la bipolaridad de la segunda mitad del siglo XX y una multipolaridad que está en proceso de consolidación. Este proceso está marcado por la aparición de unas potencias emergentes que han cobrado importancia en la definición de los asuntos globales a partir del rol cada vez más relevantes que ejercen en sus entornos regionales. En el caso de Suramérica, la potencia regional que marca el ritmo de este proceso es Brasil, que asume un rol de liderazgo y que guía un proceso de delimitación de una región suramericana.

La consolidación de Brasil como potencia líder regional ha estado acompañada de un proceso de delimitación de Suramérica como su espacio de influencia. Esta nueva definición difiere de otras concepciones del espacio continental como las de la Panamérica, la Interamérica, Las Américas e incluso, de Latinoamérica. Respecto a las primeras, Suramérica constituye una alternativa al tradicional alineamiento de la región con Estados Unidos y a la formulación de la Doctrina Monroe hecha por la superpotencia, que concibió al continente como su área de influencia. Por otra parte, el proyecto que lidera Brasil retoma varios de los elementos presentes en el Latinoamericanísmo pero no los asume por completo sino que los actualiza, les da un enfoque propio y mucho más pragmático.

Poner en la balanza al Latinoamericanísmo y al Monroísmo permite sostener que históricamente este último ha tenido más peso en la definición de los asuntos regionales. Sin embargo, el Monroísmo como rasgo definitorio de la política regional 
hasta el comienzo del siglo XXI se ha debilitado de la mano del surgimiento de la multipolaridad, de las reformulaciones de la política exterior estadounidense y la falta de una estrategia estadounidense clara de relacionamiento con el sur del continente. Paralelamente, Suramérica ha surgido como una alternativa llamativa incluso para adeptos al Monroísmo como Colombia, que están modificando su orientación. Pero esto no habría sido posible sin un cambio en las condiciones materiales que han dado a la región un peso más significativo a escala global y una consecuente diversificación de socios comerciales que ha incitado que las élites políticas y económicas de Suramérica estén cambiando ellas mismas la mentalidad monroísta.

Desde la llegada de Juan Manuel Santos a la presidencia de Colombia, el país ha empezado a tener un novedoso acercamiento al sur del continente. Debe reconocerse que el interés por la región no se puede leer como una reorientación definitiva hacia el Latinoamericanísmo, pero sí es posible identificar un replanteamiento del rol nacional ahora más activo, menos sumiso y significativamente más consciente del lugar que ocupa. De allí que se produzca una ampliación temática y geográfica de la agenda, en la que las relaciones Colombia-Brasil se nutren de nuevas temáticas y ganan intensidad.

- Es necesario que en el proyecto suramericano se fortalezca aún más el multilateralismo y se reconsidere la negativa a generar espacios de soberanía compartida. De momento, las mejores perspectivas para avanzar en ese sentido las ofrecen Mercosur y Unasur, que pueden erigirse en cabezas de una institucionalidad fuerte e interdependiente.

- Aun no hay claridad sobre la posición que asumirá Estados Unidos frente a Suramérica, pues tal como la región, la percepción de la superpotencia se encuentra en construcción. Hay algunos elementos que le agradan y otros que le incomodan. Por esto, la tradicional potencia sigue siendo una variable de suma relevancia en la definición de los asuntos de la región y aunque de momento no se ha opuesto al Suramericanísmo, este no es un rasgo definitivo. Por lo mismo, la cercanía de Colombia al proyecto brasileño no implica una orientación irreversible.

\section{Referencias}

Agencia EFE. (2000, agosto 5). Clinton visitará el Plan Colombia. www.caracol.com. co. Disponible en: http://www.caracol.com.co/noticias/clinton-visitara-el-plancolombia/20000805/nota/94327.aspx

Amorim, C. (2009). South American Integration. Diplomacy, Strategy \& Politics, 10, 5-25. Ardao, A. (2006). Panamericanismo y Latinoamericanismo. En L. Zea. América Latina en sus ideas (pp. 157-171). Mexico D.F.: Siglo XXI Editores.

Arroyave, M. (2012). La UNASUR en la estrategia regional de Colombia y Brasil. En E. Pastrana, S. Jost, y D. Flemes (Eds.). Colombia y Brasil: ¿̇socios estratégicos 
en la construcción de Suramérica? (pp. 239-282). Bogotá: Editorial Pontificia Universidad Javeriana.

Bermúdez, C. (2011). La integración regional a comienzos del siglo XXI: MERCOSUR y UNASUR. Memorias, 202-231.

Betancourt, R. (2012a). Colombia frente a los espacios regionales de cooperación e integración. En S. Jost. Colombia: ¿̇una potencia en desarrollo? (pp. 659-673). Bogotá: Konrad Adenauer Stiftung.

Betancourt, R. (2012b). El relacionamiento de Colombia y Brasil con Estados Unidos: entre el ocaso de la Doctrina Monroe y la construcción de Suramérica. En E. Pastrana, S. Jost, y D. Flemes (Eds.). Colombia y Brasil: ¿socios estratégicos en la construcción de Suramérica? (pp. 309-337). Bogotá: Editorial Pontifica Universidad Javeriana.

Boorstin, D. (1997). Compendio histórico de los Estados Unidos: un recorrido por sus documentos fundamentales. México D.F.: Fondo de Cultura Económica.

Carvajal, L. (2011). El acuerdo de cooperación militar entre Colombia y Estados Unidos: ¿disuación por soberanía? En D. Cardona. Colombia: una política exterior en transición (pp. 273-307). Bogotá: FESCOL.

CEPAL (2011). Las relaciones entre América Latina y el Caribe y sus principales socios extraregionales. En A. Bárcena, A. Pardo, O. Rosales, y R. Pérez. Panorama de la inserción internacional de América Latina y el Caribe(pp. ). Santiago de Chile: Naciones Unidas.

DANE (2012, enero). Colombia, exportaciones totales, según CIIU Rev. 3. Disponible en: http://www.dane.gov.co/index.php?option=com_content\&view=article\&i $\mathrm{d}=76 \&$ Itemid $=56$

Drekonja-Korna, G. (2011). El ocaso de la Doctrina Monroe. En Wollrad, D., Mai-hold, FGf. y Mols, M. La agenda internacional de América Latina: entre nuevas y viejas alianzas (pp. 22-30). Buenos Aires: Friederich Ebert Stiftung.

Flemes, D. (2012). Actores estatales y regionalismo estratégico: Brasil y Colombia en el orden multipolar. En E. Pastrana, S. Jost, y D. Flemes (Eds.). Colombia y Brasil: ¿socios estratégicos en la construcción de Suramérica? (pp. 25-47). Bogotá: Editorial Pontificia Universidad Javeriana.

Grabendorf, W. (2010). Brasil: de coloso regional a potencia global. Revista Nueva Sociedad, 154-171.

Gudynas, E. (2006). El camino de la integración sudamericana . CLAES - D3e. Disponible en: http://www.fundesnap.org/files/cumbresudamericanaclaesceades.pdf 
Guerra-Barón, A. (2012). Colombia y Brasil: un análisis desde la perspectiva económica. En E. Pastrana, S. Jost, y D. Flemes (Eds.). Colombia y Brasil: ¿́socios estratégicos en la construcción de Suramérica? (pp. 387-421). Bogotá: Editorial Pontificia Universidad Javeriana.

Haas, E. (1970). The study of regional integration. International Organization, 610.

Hakim, P. (2011). ¿Por qué Estados Unidos y Brasil no tienen buena relación? . Foreign Affairs Latinoamérica 11, 14-21.

Herrera, B. (2011). La proyección regional y mundial de Brasil: un desafío para la política exterior del Estado colombiano. En E. Pastrana, S. Jost, y M. L. Márquez, Más allá de la seguridad democrática. Agenda hacia nuevos horizontes (pp. 475-484). Bogotá: Konrad Adenauer Stiftung.

Herrera, B. (2012). La gobernabilidad global y las perspectivas de los Estados brasileño y colombiano. En E. Pastrana, S. Jost, y D. Flemes (Eds.). Colombia y Brasil: ¿Socios estratégicos en la construcción de Suramérica? (pp. 367-386). Bogotá: Editorial Pontificia Universidad Javeriana.

Hirst, M. (2004). Brasil ante el conflicto colombiano. En Dimensiones territoriales de la guerra y la paz (pp. 119-124). Bogotá: Red de Estudios de Espacio y Territorio (RET) de la Universidad Nacional.

Hirst, M. (2011). Brazil's renewed responsibilities in cooperation for development and international security. En Sherman, J.; Gleason, M.M; Sidhu, W.P.S y Jones, B. (Eds.) Engagement on Development and Security: New Actors, New Debates. Nueva York: NYU-Center on International Cooperation.

Huntington, S. (2006). ¿Choque de civilizaciones? Madrid: TECNOS.

Hurrell, A. (2000). Some Reflections on the Role of Intermediate Powers in International Institutions. En W. W. Centre. Paths to Power: Foreign Policy Strategies of Intermediate States, Working Paper, 244 (pp. 23-41). Washington: Woodrow Wilson International Center.

Keohane, R., y Nye, J. (1988). Poder e interdependencia. La política mundial en transición. Buenos Aires: GEL.

Kissinger, H. (2001). Does America Need a Foreign Policy? Toward a Diplomacy for the 21st. Century. Nueva York: Simon and Shuster.

Lafer, C. (2002). La identidad internacional de Brasil . Buenos Aires: Fondo de Cultura Economica.

Liévano Aguirre, I. (1988). Bolivarismo y Monroismo. Bogotá: Tercer Mundo Editores. 
Londoño, J. F. (2011). Colombia y Estados Unidos: ¿Una relación por revisar? En D. Cardona, Colombia: Una política exterior en transición (pp. 235-272). Bogotá: FESCOL.

Moniz, L. A. (2006). Brazil as a Regional Power and Its Relations with the United States. Latin American Perspectives, 33(3), 12-27.

Pastrana, E. (2011a). Evolución y perspectivas de las relaciones entre Colombia y Brasil. En B. Sorj, y S. Fausto. Brasil y América del sur: miradas cruzadas (pp. 76-116). Buenos Aires: Plataforma Democrática.

Pastrana, E. (2011b). La política exterior colombiana hacia Sudamérica: de Uribe a Santos. IX Curso para Diplomáticos Sudamericanos. Rio de Janeiro: Fundaçao Alexandre de Gusmão (FUNAG).

Pastrana, E. (2012). La política exterior colombiana y la percepción de los expertos: ¿cambio o continuidad en la era Santos? KAS Paper No. 15. Bogotá: Konrad Adenauer Stiftung.

Pastrana, E., y Vera, D. (2012a). Los desafíos de Colombia frente a la proyección de Brasil como potencia regional y jugador global. En S. Jost. Colombia: ¿Una potencia en desarrollo? escenarios y desafios para su política exterior (pp. 613-641). Bogotá: Konrad Adenauer Stiftung.

Pastrana, E., y Vera, D. (2012b). Rasgos de la política exterior brasileña en su proceso de ascenso como potencia regional y jugador global. En E. Pastrana, S. Jost, y D. Flemes. Colombia y Brasil: ¿́socios estratégicos en la construcción de Suramérica? (pp. 135-185). Bogotá: Editorial Pontificia Universidad Javeriana.

Pastrana, E., y Vera, D. (2012c). De Uribe a Santos: ¿Continuidad o nueva orientación de la política exterior Colombiana? En S. Jost. Colombia: ¿Una potencia en desarrollo? Escenarios y desafíos para su política exterior (pp. 57-79). Bogotá: Konrad Adenauer Stiftung.

Ramírez, S. (2007). Colombia y Brasil: una lenta y paradójica aproximación. En W. Hofmeister, F. Rojas, y L. G. Solís. La percepción de Brasil en el contexto internacional: perspectivas y desafíos. Tomo 1: América Latina (pp. 135-174). Rio de Janeiro: Konrad Adenauer Stiftung.

Ramírez, S. (2011). América Latina y el Caribe: diferenciación y acercamiento. En D. Cardona. Colombia: una política exterior en transición (pp. 125-144). Bogotá: FESCOL.

Rocha, A., y Morales, D. (2008). El sistema político internacional de post-Guerra Fría y el rol de las potencias regionales mediadoras. Los casos de Brasil y Mexico. Espiral, 23-75. 
Roett, R. (2007). Brasil y Estados Unidos. En W. Hofmeister, F. Rojas, y L. G. Solís, La percepción de Brasil en el contexto internacional: Perspectivas y desafios. Tomo 2. (pp. 47-65). Rio de Janeiro: Konrad Adenauer Stiftung.

Salcedo, F. (2011). Anexos Estadisticos. En D. Cardona, Colombia: una política exterior en transición (pp. 311-460). Bogotá: FESCOL.

Sánchez, F., y Monroy, C. (2012). Actores, decisión y construcción de la política exterior colombiana hacia los Estados Unidos en la era Santos. En S. Jost. Colombia: ¿una potencia en desarrollo? Escenarios y desafíos para su política exterior (pp. 323-335). Bogotá: Konrad Adenauer Stiftung.

Smith, G. (1994). The Last Years of the Monroe Doctrine, 1945-1993. Nueva York: The Last Years of the Monroe Doctrine, 1945-1993.

Sorj, B., y Fausto, S. (2011). El papel de Brasil en América del Sur. En B. Sorj, y S. Fausto. Brasil y América del Sur: Miradas cruzadas (pp. 5-34). Buenos Aires: Plataforma Democrática.

Sorj, B., y Fausto, S. (2013). Brasil: actor geopolítico regional y global. En B. Sorj, y S. Fausto, Brasil y América Latina: ¿Qué Liderazgo es Posible? (pp. 23-68). São Paulo: Centro Edelstein de Pesquisas Sociais y Fundação Instituto Fernando Henrique Cardoso.

Spektor, M. (2011). El regionalismo de Brasil. En B. Sorj, y S. Fausto. Brasil y América del Sur: miradas cruzadas (pp. 161-198). Buenos Aires: Plataforma Democrática.

Telesur.com (2012, diciembre 26). Justicia Electoral de Paraguay acepta misión de observación de la Unasur. Telesur.com. Disponible en: http://www.telesurtv. net/articulos/2012/12/26/justicia-electoral-de-paraguay-acepta-mision-deobservacion-de-la-unasur-5042.html.

The White House. (2010). National Security Strategy. Washington: Seal of the President of the United States.

Tickner, A. (2007, enero-junio). Intervención por invitación, claves de la política exterior colombiana y de sus debilidades principales. Colombia Internacional, 65, 90-111.

Tokatlian, J. G. (2009, enero 8). http://www.project-syndicate.org. Disponible en: http:// www.project-syndicate.org/commentary/the-end-of-the-monroe-doctrine/spanish

Weisstaub, L. (2006). Principios del diálogo político: Cooperación para el desarrollo. América Latina-Union Europea. Cartagena: Escuela Latinoamericana de Cooperacion y Desarrollo-Universidad San Buenaventura . 
